\title{
Desafios para a produção orgânica do ERJ
}

\author{
René de Carvalho*
}

\begin{abstract}
RESUMO
O artigo discute o desenvolvimento recente da agricultura orgânica no Estado do Rio de Janeiro, enfatizando os fatores explicativos da sua relativa estagnação, relacionada à incompletude de sua cadeia produtiva e ao pouco domínio exercido sobre suas condições de expansão no tocante à capacidade de conquistar novos mercados e à produção de inovações tecnológicas. Busca-se também agregar à discussão algumas sugestões e propostas voltadas a pavimentar uma trajetória de crescimento e consolidação da produção orgânica estadual. $\mathrm{O}$ estudo é composto por quatro partes, que contemplam uma análise da importância da PO para a economia estadual, a contextualização dos pontos de estrangulamento tecnológicos e econômicos identificados pelos atores, a caracterização do entorno institucional da PO estadual e das políticas públicas de apoio ao setor.
\end{abstract}

Palavras-chave: Agricultura Orgânica; Cadeia Produtiva; Pontos de Estrangulamento; Inovação Tecnológica

\begin{abstract}
This article discusses the recent development of organic agriculture in the state of Rio de Janeiro. It emphasizes the factors explaining its relative stagnation, pertaining to its incomplete productive chain and to the little control over expansion possibilities concerning technological innovation and new market niches that should be exploited. Some suggestions and proposals will also be presented, aimed at contributing to an itinerary of growth and consolidation of organic production (OP) in the state. This study has four sections: an analysis of the importance of OP to the state economy; the contextualization of technological and economical bottle necks identified by the agents; the characterization of the institutional environment of the state OP, and of the public policies supporting the sector.
\end{abstract}

Keywords: Organic Agriculture; Productive Chain; Bottle Necks; Technological Innovation

\footnotetext{
*Professor Associado do IE-UFRJ. renecarv@ centroin.com.br
} 


\section{Introdução}

A produção orgânica - agricultura, criação animal, produção de flores, mel, de insumos orgânicos e transformação industrial - é vista como um dos setores do complexo alimentar do estado com mais elevado potencial de crescimento. Essa expectativa apoia-se na emergência de um novo padrão de consumo preocupado com a qualidade dos alimentos e a consequente evolução da demanda de produtos orgânicos nos países de alta renda (PAR) (Buanain, 2007). E na avaliação de que, apesar de expressivas diferenças de renda e informação com relação àqueles países, metrópoles como Rio de Janeiro e São Paulo dispõem de condições socioeconômicas favoráveis à expansão da demanda por produtos orgânicos (Ormond, 2002).

Entre as condições favoráveis à expansão da PO fluminense é necessário também incluir vantagens de cunho institucional e o dinamismo de seus atores. Apesar de uma escala de produção ainda restrita, a PO dispõe de uma relativa densidade institucional - Instituições de Apoio, de Ensino e Pesquisa - e diversas instâncias de coordenação. Desse modo, os produtores orgânicos, suas organizações e empresas construíram, nos últimos trinta e cinco anos, uma bela história de lutas e conquistas (Fonseca e Assis, 2007).

Apesar dessas expectativas, o crescimento da produção orgânica fluminense foi pouco expressivo na última década. Os principais estudos sobre o tema apontam as dificuldades de comercialização como principal causa dessa relativa estagnação. Para Fonseca (2007) a comercialização é o principal condicionante do crescimento do setor, e a relativa estagnação da PO nesse período deve-se à sucessão de fases de expansão e retração que marcaram sua evolução recente. Os períodos de expansão do setor foram marcados pelo acesso a novos canais de comercialização. A abertura de novos canais de comercialização seria assim uma condição necessária à expansão do setor.

A escassa divulgação das qualidades da PO é também apontada como entrave ao crescimento do setor. As limitações de escala, a fragilidade econômica dos produtores (em sua maioria pequenos produtores familiares), as dificuldades de acesso ao crédito e à assistência técnica são também indicados como fatores que afetam negativamente o crescimento do setor (Fonseca, 2007). Osmond (2002) acrescenta à lista de entraves que afetam o setor a falta de embalagens adequadas e as dificuldades de certificação. A dispersão das pesquisas e a falta de apoio ao sistema de produção também dificultam a expansão da produção orgânica (Melão et allii - IPARDES, 2007). 
Estudos recentes agregam novas explicações para a relativa estagnação da PO fluminense. Pesquisa realizada para a Rede de Tecnologia do ERJ (Carvalho, 2011) reafirma as dificuldades comerciais de acesso à assistência técnica, a financiamento e a insumos orgânicos como causas da limitada expansão produtiva. A ênfase do estudo volta-se, entretanto, para duas limitações estruturais da PO fluminense: a incompletude de sua cadeia produtiva no estado - limitada fundamentalmente à produção de frutas, verduras e legumes e o pouco domínio da $\mathrm{PO}$ sobre suas condições de expansão no tocante à capacidade de conquistar novos mercados e à produção de inovações tecnológicas. Se essa avaliação é correta, seria o mesmo que dizer que essas dificuldades estruturais dificultam uma expansão da PO realizada apenas com suas próprias forças. Ela não poderia prescindir do apoio de outros atores para efetivamente se expandir.

A hipótese que orienta este estudo é de que os principais pontos de estrangulamento apontados pela literatura, inclusive os estruturais, são reais, mas seriam mais bem compreendidos se analisados no contexto da evolução da agricultura orgânica e, em particular, da fase em que ela se encontra. A principal característica da fase atual seria que a expansão da PO está principalmente condicionada a avanços no processo de construção de seu mercado, à passagem de uma demanda formada por consumidores já informados e sensíveis aos princípios da produção orgânica aos consumidores não informados.

Este estudo tem por objetivo contribuir, a partir dessa hipótese, para o melhor entendimento das causas da contradição entre expectativas de crescimento e o fraco desempenho da PO estadual. Tem também a intenção de agregar à discussão algumas sugestões e propostas voltadas a pavimentar uma trajetória de crescimento e consolidação da produção orgânica estadual.

Além desta Introdução, o estudo é composto por quatro partes, que contemplam uma análise da importância da PO para a economia estadual, a contextualização dos pontos de estrangulamento tecnológicos e econômicos identificados pelos atores, a caracterização do entorno institucional da PO estadual e das políticas públicas de apoio ao setor.

\section{A produção orgânica e a economia fluminense}

A produção de base agropecuária é pouco expressiva no ERJ. Contribuem para esse resultado a limitação de áreas planas mecanizáveis disponíveis no Estado e o limitado desenvolvimento das atividades de segunda industrialização e de produtos de qualidade 
diferenciada (Carvalho, 2005). Diferentemente da produção agrícola e do primeiro processamento, a segunda industrialização é menos dependente da base produtiva regional e se localiza preferencialmente junto aos grandes mercados.

A principal característica do complexo alimentar do Rio de Janeiro é a macrocefalia do comércio atacadista e varejista. Apesar de ser o segundo mercado do país, o Rio de Janeiro quase não oferece espaços para a comercialização da produção regional. Os produtos de qualidade diferenciada têm grande espaço potencial no estado, embora sua produção ainda seja incipiente. Setor mais expressivo da produção de qualidade hoje, a produção orgânica poderia se constituir em importante vetor do desenvolvimento de outros produtos de qualidade diferenciada no estado.

Além de suas importantes vantagens para a saúde do consumidor e preservação do meio ambiente e da saúde dos trabalhadores, a produção orgânica pode também desempenhar um papel importante na revitalização da produção alimentar fluminense.

\subsection{A evolução da PO estadual}

A produção orgânica do Rio de Janeiro desenvolveu-se a partir do movimento agroecológico e da ação conjunta de consumidores, pesquisadores e produtores que compartilham essa preocupação. É difícil separar as principais etapas de sua evolução das ações e tenacidade do movimento orgânico estadual e seu comprometimento com a saúde e a qualidade de vida dos consumidores e trabalhadores rurais bem como pela preservação ambiental.

As primeiras ações voltadas à produção orgânica têm início no estado em 1981, por iniciativa da COONATURA, ONG fundada em 1979 com o objetivo de congregar as pessoas descontentes com a contaminação dos alimentos oferecidos à população. Uma segunda entidade, a ABIO, organização civil sem fins lucrativos, é criada em 1985, passando a se dedicar à capacitação técnica da agricultura orgânica e ao fortalecimento das atividades produtivas.

O ano de 1992 é marcado pela criação da Fazendinha agroecológica, parceria entre a Agroecologia da EMBRAPA e a UFRRJ. A Fazendinha tornou-se o principal centro de divulgação e capacitação da produção orgânica no estado.

A primeira feira de produtos orgânicos do estado (feira cultural e ecológica) foi organizada em 1994 e começou a funcionar, no bairro da Glória, na capital do estado. Em 
1998 é criada a Rede Agroecológica do RJ, formada por sete instituições públicas e privadas, que se uniram com o objetivo de gerar e adequar tecnologias agroecológicas, apoiando o credenciamento de produtores e a comercialização de produtos agroecológicos (Fonseca, 2005).

A entrada de produtos orgânicos em redes de supermercado do Rio de Janeiro também resultou da ação de pesquisadores e associações de agricultores orgânicos. A abertura desse canal de comercialização permitiu importante crescimento da produção orgânica estadual e o surgimento/crescimento de empresas e associações de produtores.

Após as grandes dificuldades enfrentadas pelos distribuidores de produtos orgânicos junto aos supermercados e sua retração (que serão analisadas posteriormente), que ocasionou forte queda da produção, foram as organizações agrobiológicas, em particular a ABIO, que conquistaram a abertura e consolidação de novos canais de comercialização - no caso a ampliação das feiras orgânicas no Município do Rio de Janeiro.

O desenvolvimento da certificação associativa a partir da $\mathrm{ABIO}$, buscando viabilizar a entrada de novos produtores sem condições de pagar os elevados custos da certificação orgânica, põe mais uma vez em evidência o papel central desempenhado pelo movimento agroecológico na trajetória da produção orgânica estadual.

A força do movimento agroecológico também influenciou a criação de órgãos de coordenação da cadeia produtiva: a Câmara Setorial da Agricultura Orgânica, junto à Secretaria Estadual de Agricultura e as coordenações de orgânicos junto ao MAPA Ministério da Agricultura, Pecuária e Abastecimento (CTAO - Coordenação Técnica de Agricultura Orgânica) e ao MDA - Ministério do Desenvolvimento Agrário. Participam também dessas coordenações a SNA - Sociedade Nacional de Agricultura, que desenvolve atividades de apoio à produção orgânica no país e no Rio de Janeiro, e o SEBRAE - Serviço Brasileiro de Apoio às Micro e Pequenas Empresas, ao qual estão ligados vários grupos de produção orgânica no estado.

\section{Os pontos de estrangulamento da produção orgânica estadual}

Nosso ponto de partida, nesta análise, será a discussão da visão dos produtores sobre pontos de estrangulamento da produção orgânica estadual, conforme expressa no estudo da Rede de Tecnologia do ERJ (Carvalho, 2011). 
Chama inicialmente a atenção, nos resultados, o fato de que os produtores entrevistados não se limitaram, em suas respostas, a identificar os pontos de estrangulamento tecnológico da produção, conforme era solicitado. Eles associaram sistematicamente obstáculos tecnológicos e não tecnológicos ao crescimento da produção. Poder-se-ia pensar, à primeira vista, tratar-se de uma subestimação da questão tecnológica por parte dos produtores. Mas é mais provável que a estreita vinculação entre os gargalos econômicos e tecnológicos seja principalmente resultado da fase em que se encontra a PO estadual e, em particular, de sua escala ainda reduzida de produção e da incompletude de sua cadeia produtiva.

Vista de perto, a relação entre inovação tecnológica e escala de produção parece assumir na PO fluminense a forma de uma determinação recíproca: a oferta de inovações tecnológicas é uma condição necessária para o aumento da produção e sua diversificação. Mas a atual escala e diversidade da produção inibem a formação de empreendimentos nos setores de produção de medicamentos, vacinas, controle biológico de pragas e sementes de qualidade, entre outros.

A produção de insumos orgânicos condiciona a evolução da competitividade da PO e sua capacidade de conquistar novos mercados. A elevação da produtividade, a melhor adequação da produção ao mercado e a diminuição de custos dependem muito da oferta de inovações tecnológicas. A pesquisa também condiciona a diversificação da oferta e, em particular, o credenciamento de novos setores produtivos (vacinas e medicamentos orgânicos, conservantes, rações orgânicas) e sua expansão.

O esforço de pesquisa e seu financiamento estão submetidos, em suas definições de prioridade, à importância econômica dos setores produtivos. A pesquisa dispõe, entretanto, de uma relativa autonomia de ação, principalmente em função do peso das instituições públicas de pesquisa e financiamento.

A forma de romper o impasse trazido por essa determinação recíproca é considerar que a pesquisa, no atual contexto da produção orgânica, necessita se antecipar à produção. Ela poderia, então, tornar-se uma fonte estratégica de criação de externalidades capazes de dinamizar o setor. Uma adequada oferta de inovações tecnológicas seria uma condição necessária para tornar a produção orgânica um setor mais atraente e competitivo.

\subsection{Os gargalos econômicos da produção orgânica}


A ampliação dos canais de comercialização ocupa um papel de destaque entre os pontos de estrangulamento econômico da PO fluminense. A precariedade da assistência técnica recebida pelos produtores, as dificuldades de acesso a financiamento e a pouca divulgação das qualidades da produção orgânica completam o quadro de gargalos econômicos traçado pelos produtores. Não são problemas exclusivos da produção orgânica, pois vários deles podem ser encontrados em outros setores produtivos em sua fase de crescimento e ainda caracterizados por uma escala restrita de produção.

\subsubsection{A comercialização dos produtos orgânicos}

A produção mercantil só se viabiliza quando encontra compradores. A comercialização é o momento da verdade que condiciona a reprodução da produção e a escala em que esta se dará. A afirmação de que a expansão da produção decorre da ampliação/abertura de mercados é consensual. A comercialização define a escala da produção.

Os diferentes canais de comercialização dos produtos orgânicos podem ser grupados em dois blocos: os que dão acesso a consumidores já informados e os frequentados pela maioria dos consumidores. Os canais de comercialização voltados aos consumidores informados - cestas em domicílio, feiras orgânicas, lojas especializadas - envolvem um número mais modesto de produtores. A grande maioria dos consumidores faz compras nas lojas do grande varejo. A ampliação do número de feiras e de cestas em domicílio e o processamento de frutas e legumes orgânicos podem levar ao aumento da produção. Mas é o acesso e convencimento de consumidores não informados que permite uma maior ampliação das vendas de orgânicos.

A entrada dos produtos orgânicos em lojas do grande varejo ou mercados institucionais é com frequência analisada apenas como abertura de um novo canal de comercialização. Mas é importante salientar que, para que isso ocorra, são necessárias transformações do setor produtivo e da logística, pois um maior grau de organização determina a possibilidade de garantir presença nessas lojas.

Do ponto de vista da construção do mercado de orgânicos, a entrada nos supermercados é uma etapa estratégica para a consolidação do setor. É um processo complexo que necessita de preparação. Podemos assimilá-lo a uma esfinge: ou suas características são decifradas ou ela terminará devorando os fornecedores de produtos orgânicos. A grande questão trazida pela entrada dos produtos orgânicos nas redes varejistas é que essa entrada 
para se consolidar necessita ser uma expressão da construção do mercado de produtos orgânicos.

A união indissolúvel entre o grau de organização da oferta e a utilização de canais comerciais dotados de maior escala é o principal ensinamento que pode ser tirado dos percalços que marcaram a entrada da $\mathrm{PO}$ em redes de supermercado. É também necessário dizer que as condições draconianas impostas pelo grande varejo aos produtores orgânicos que acompanharam a experiência de venda de produtos orgânicos em supermercados, a partir de 1995, também estão na origem das dificuldades enfrentadas então pela produção orgânica.

Fornecedores orgânicos ainda em fase inicial de relação com o varejo deviam abastecer as gôndolas duas vezes ao dia e aceitar os produtos não vendidos no dia como perdas imputadas ao fornecedor. A rede varejista também definia os preços de compra aos fornecedores e de venda aos consumidores. Essas regras, aplicadas a fornecedores ainda em fase de construção, prenunciavam a crônica de uma morte anunciada.

Os produtos orgânicos entram no mercado como produtos de qualidade diferenciada, alternativos à produção alimentar corrente. Essas diferenças não são aparentes nem perceptíveis pelo aspecto, cheiro ou gosto. Para que o consumidor as identifique o produto necessita ter uma certificação. Para comprar o produto, o consumidor também necessita estar sensibilizado para os benefícios que seu consumo trará por ser resultado de um processo produtivo que preserva a natureza e beneficia a saúde dos consumidores e produtores.

O mercado dos produtos diferenciados é uma construção social (Fonseca, 2005). Produtor e consumidor necessitam construir uma relação de afinidade e de confiança. A informação ao consumidor sobre as qualidades da mercadoria é essencial a essa construção. A divulgação das qualidades do produto - na embalagem do produto, dentro do supermercado e através dos meios de comunicação - é uma forma de pôr em contato o produto e o consumidor.

A informação relativa à qualidade diferenciada pode ser feita pelas empresas a partir da embalagem, da publicidade, de promoções e degustações. O mesmo critério pode ser aplicado a produtos ou marcas específicas da produção orgânica. Mas a informação dos riscos a que pode se expor o consumidor e a averiguação permanente da conformidade dos alimentos com os limites de presença de restos químicos determinados pela lei é uma informação de saúde pública. ${ }^{1}$

\footnotetext{
${ }^{1}$ Segundo o relatório da ANVISA (órgão federal de segurança sanitária) de 2012, apenas 13 alimentos são analisados pelo órgão, quando, na Europa e Estados Unidos, são analisados 300 produtos alimentares. A mesma
} 
A informação sobre os riscos que a ingestão de alimentos originados de práticas industriais e sem controle eficaz de eventuais excessos de resquícios químicos deve ser objeto de divulgação institucional. Se os consumidores não conhecem os riscos a que podem estar sujeitos e as diferenças de qualidade dos alimentos orgânicos, estes se tornam produtos de qualidade não identificada. Quando isto ocorre, os produtos orgânicos perdem sua razão de ser.

A percepção que os consumidores têm dos riscos do consumo de alimentos é determinada pela informação que recebem e pelos movimentos da opinião pública. As preocupações causadas pela informação de uso de conservantes com potencial cancerígeno, do teor em mercúrio de peixes de determinadas procedências e, depois, da contaminação de carne bovina pela "vaca louca" causaram forte impressão e levaram à mobilização dos consumidores. Essa evolução, entretanto, foi interrompida. A crise econômica e, no caso brasileiro, a importância crescente das exportações de alimentos e a inserção de numerosas famílias ao mercado de consumo, além da falta de fiscalização sanitária, produziram um deslocamento das preocupações alimentares da qualidade e dos benefícios à saúde para temas apenas quantitativos: oferta e preços.

Tinha-se então a impressão da existência de uma expressiva demanda potencial apenas à espera de encontrar produtos alimentares de qualidade para procederem à compra. Esse movimento não foi, entretanto, consolidado pela produção orgânica e pela informação institucional. O principal ensinamento que pode ser tirado é que a construção do mercado orgânico não pode ser vista como um quase processo natural. Ao contrário, essa construção necessita de uma permanente mobilização dos produtores.

A presença de produtos orgânicos em gôndolas do supermercado foi assim uma condição necessária, mas insuficiente para a conquista e fidelização de novos clientes. Faltou a divulgação das qualidades dos produtos de forma convincente aos potenciais compradores. Só reconhecendo essas qualidades eles se disporiam a pagar um preço superior para acessálos. A construção do mercado de produtos orgânicos resulta da ação permanente dos produtores e da contínua sedução de sua demanda potencial.

Preços mais elevados numa conjuntura centrada em aspectos quantitativos parecem também situar os produtos orgânicos na contramão das tendências em curso. Percebe-se, no

reportagem indica que metade da carne comercializada no país não tem certificado de inspeção federal (CIF) $(O$ Globo, 30 de janeiro de 2014). 
entanto, uma falsa contradição: é possível que o consumidor venha se preocupar com quantidades e preços e ainda mais - pois cresce o número de consumidores - com a adequação dos alimentos à saúde do consumidor.

\subsubsection{Escalas de comercialização}

A venda no grande varejo traz muitas exigências aos produtores, em particular no caso de frutas, legumes e verduras (FLV), que são o principal vetor da produção orgânica do estado. Os produtores necessitam dispor de escalas de oferta elevadas e regulares, abastecer as gôndolas duas vezes ao dia e realizar viagens quase diárias entre os locais de produção e as lojas da rede de supermercado. A maior escala de vendas encontra-se condicionada à organização de uma nova logística. Esta exige um grande investimento que independe, num primeiro momento, da quantidade transportada. A nova logística é uma condição necessária que onera fortemente os custos até a obtenção de uma escala de venda mais elevada. Maior periodicidade da oferta e maior escala de comercialização exigem também uma nova organização dos produtores, mais centrada na cooperação e no planejamento da produção.

O abastecimento de mercados institucionais - como merenda escolar - traz também exigências logísticas e organizativas. Se, em termos de apresentação dos produtos e abastecimento das gôndolas, as exigências são menores do que nos supermercados, a qualidade dos produtos, a regularidade e a diversidade da oferta permanecem necessárias. Por permitir uma escala expressiva de vendas e apresentar custos logísticos menores, os mercados institucionais podem ser vistos como uma fase preparatória, anterior a uma presença sistemática em grandes lojas do varejo. A mobilização desses mercados corresponde, assim, a uma fase em que a produção orgânica poderia "adquirir musculatura" para prosseguir na construção de seu mercado.

\subsection{Assistência técnica e financiamento à produção}

Capacitação e apoio técnico à produção são fatores essenciais à diminuição dos custos de produção e melhoria da qualidade dos produtos. A assistência técnica é responsável pela difusão das inovações tecnológicas e divulgação das boas práticas agropecuárias. É também o principal canal que articula pesquisa e produção. Sua importância é ainda maior quando atua em um ambiente onde a maioria dos produtores e responsáveis de empresa aprendeu a 
produção orgânica na prática ou combinando-a com a leitura de textos técnicos e têm pouco acesso a instrumentos de atualização técnica e tecnológica (Carvalho, 2011).

É muito pequeno hoje o número de profissionais formados em agropecuária e veterinária orgânica no estado. Essa limitação reflete as dimensões reduzidas da demanda dessa especialidade, mas também a pequena importância atribuída pelo órgão estadual de assistência técnica à difusão da agricultura orgânica. A criação de um departamento especializado em produção orgânica na EMATER-RJ (empresa responsável pela assistência técnica e extensão rural no Estado do Rio de Janeiro) poderia se constituir em ponto de partida para uma maior formação de técnicos com essas especialidades. 


\subsubsection{Financiamento}

A maioria dos agricultores orgânicos do estado tem valor de vendas anual compatível com o acesso a empréstimos do PRONAF, programa voltado ao apoio à agricultura familiar. A produção orgânica apresenta, entretanto, especificidades que dificultam seu acesso a essa importante fonte de crédito (Fonseca, 2005). Na agricultura tradicional as compras de insumo impactam fortemente os gastos com a produção. Já na agricultura orgânica predomina a autoprodução de insumos. Os ciclos curtos da produção hortícola também não se adaptam bem aos prazos de desembolso e de quitação dos empréstimos.

Uma importante especificidade relativa às condições de financiamento refere-se ao período de transição para a agricultura orgânica, que dura em torno de três anos. O financiamento dessa fase teria grande impacto para minorar as dificuldades enfrentadas pelos agricultores em transição. Estes não podem vender seus produtos com o selo orgânico durante essa transição.

A falta de financiamento da transição afeta a capacidade de pronta resposta da produção orgânica às elevações da demanda. Além disso, essa ausência dificulta a construção de uma reserva de terras credenciadas e aptas a entrar rapidamente em produção. A adaptação do crédito do PRONAF às culturas perenes é outra necessidade, pois se agrega ao período de transição o de maturação da planta, aumentando o número de anos em que o produtor é pouco remunerado.

Os produtores orgânicos de origem urbana têm também seu acesso ao crédito dificultado pela importância das rendas de origem urbana em sua remuneração mensal. Os salários e pensões percebidas por esses produtores ultrapassam o limite de $20 \%$ da renda mensal, embora suas vendas agrícolas situem-se dentro dos limites do PRONAF.

O crescimento da produção orgânica requer, assim, mecanismos específicos de crédito a ela adaptados no PRONAF e a formação de um departamento técnico especializado em produção orgânica na EMATER.

\section{Os principais gargalos tecnológicos da produção orgânica fluminense}

Ainda em Carvalho (2011) vê-se que os produtores orgânicos identificam a presença de gargalos tecnológicos em todas as etapas produtivas e subsetores da produção orgânica. $\mathrm{O}$ acesso a insumos produtivos (sementes orgânicas de qualidade, rações alimentares e a matérias-primas orgânicas), a prevenção e tratamento orgânico de doenças e pragas e a 
conservantes orgânicos para processamento industrial foram identificados como os principais pontos de estrangulamento técnico enfrentados pelos produtores.

As prioridades de pesquisa apontadas por cada produtor compõem um quadro geral que mostra como as dificuldades tecnológicas da PO se refletem negativamente sobre sua capacidade de diversificação e expansão da produção. A expansão da produção requer sementes orgânicas mais produtivas e melhor adaptadas às regiões de cultivo, insumos para o controle biológico de pragas, novos fertilizantes orgânicos, embalagens biodegradáveis e técnicas de cultivo protegido.

A evolução da pesquisa e da produção de insumos também condiciona a ampliação da cadeia produtiva de orgânicos. A certificação da produção orgânica animal - carne de frango e bovinos, derivados do leite - depende muito do desenvolvimento de pesquisas e da produção de insumos para as rações orgânicas e de vacinas e medicamentos orgânicos. A expansão da produção e a melhoria de sua produtividade demandam orientações sobre a melhoria das pastagens naturais e estão condicionadas ao acesso a material genético de qualidade.

O fortalecimento da agroindústria orgânica é, por sua vez, limitado pela quase inexistente oferta de matérias-primas orgânicas produzidas na região. Elas podem ser encontradas em outros estados, mas a preços muito mais elevados - agravados ainda pelo custo de transporte - e não há garantia de continuidade da oferta. $\mathrm{O}$ acesso às matérias-primas se constitui hoje em barreira à entrada no setor. O processamento industrial orgânico é também limitado pela falta de estabilizadores e conservantes compatíveis com o caráter orgânico da produção.

\subsection{Acesso a material genético de qualidade}

A maioria das sementes hoje utilizadas na produção orgânica é convencional. Nos próximos anos o uso de sementes orgânicas certificadas será obrigatório. O fornecimento de sementes certificadas no horizonte atual, frente à fragilidade de sua produção, tende a constituir-se em importante ponto de estrangulamento para a produção. A produção e fornecimento de sementes orgânicas são potencialmente uma atividade rentável. A busca de variedades mais produtivas, de maturação mais lenta ou rápida, e de variedades resistentes a climas específicos deverá crescer fortemente. 
As dificuldades de acesso a sementes orgânicas de qualidade e diversificadas impactam diretamente a produtividade e a capacidade de diferenciação da oferta. Não se pode esperar que sementes tradicionais, produzidas para responder aos estímulos agroquímicos, respondam de forma apropriada ao manejo orgânico.

Além do acesso a insumos, os produtores enfrentam também grandes dificuldades de obtenção de produtos voltados à prevenção e ao tratamento orgânico de doenças e pragas. Ou seja: duas das principais etapas da produção não dispõem de um apoio tecnológico consistente.

Esse gargalo é percebido de forma diferenciada pelos produtores (Carvalho, 2011). É muito sentido nos setores de produção de insumos e de transformação industrial, mas é minimizado pela maioria dos produtores agrícolas. Estes afirmam não ter enfrentado problemas de doenças e pragas em seus cultivos. O principal argumento utilizado é que o manejo orgânico fortalece a capacidade de resistência das plantas e evita a atração de pragas.

No momento a presença de doenças e pragas na agropecuária orgânica do estado é ainda restrita, como a escala da produção. Seria, entretanto, um grande risco pensar que a ampliação e diversificação da produção não tenderão a ser acompanhadas por maior incidência de doenças e pragas.

A irregularidade da oferta de produtos orgânicos é considerada, com frequência, uma das principais fragilidades da comercialização de produtos orgânicos. A ampliação dos cultivos protegidos seria um importante fator de regularização da oferta.

A oferta de insumos orgânicos aos subsetores da produção orgânica deve enfrentar, também, sua necessidade de viabilização econômica, baseada em uma escala mínima de demanda. Esta pode ser obtida por pelo menos duas formas. A fabricação de insumos para a produção orgânica para ser economicamente viável necessitaria voltar-se ao mercado orgânico nacional. Empreendimentos tecnológicos de menor porte, empresas incubadas em universidades teriam interesse em produzir para uma demanda ainda pequena, mas cuja expansão a empresa poderá acompanhar.

A conclusão a que se impõe é que a pesquisa e a produção de insumos orgânicos - em particular sementes de qualidade, meios de combate biológico a doenças e pragas, vacinas e medicamentos orgânicos para a criação animal e embalagens biodegradáveis - são um elemento-chave do crescimento e consolidação da produção orgânica estadual. Como visto, seria importante que essas atividades precedessem à implantação e ao crescimento das 
culturas, pois a produção orgânica fluminense, em sua fase atual, ainda não domina muitas das condições de sua expansão e diversificação. 


\section{A governança da cadeia produtiva e os atuais desafios da produção orgânica}

A produção orgânica dispõe, como visto, de um denso ambiente institucional e construiu várias instâncias de coordenação. A principal delas, a Câmara Setorial da Agricultura Orgânica, junto à Secretaria Estadual de Agricultura, é o órgão de representação da produção orgânica e suas instituições de apoio junto ao governo do Estado. Ela está voltada principalmente à proposição e avaliação de políticas públicas setoriais. A CTAO, Coordenação técnica da agricultura orgânica, coordena instituições de pesquisa e representações dos produtores junto à DR-MAPA (Delegacia Regional do Ministério da Agricultura) e busca principalmente dar resposta às dificuldades técnicas enfrentadas no dia a dia pelos produtores.

A articulação da produção orgânica junto ao MDA cumpre funções similares. Mesmo dispondo de poucos recursos financeiros e humanos, estas duas coordenações produziram bons resultados, a partir do esforço e conhecimentos dos técnicos lotados nesses órgãos.

O governo estadual desenvolve um programa específico de apoio à produção orgânica: o Cultivar Orgânico. O programa se dirige a agricultura, pecuária e produção de sementes e mudas orgânicas e oferece financiamento para custeio e investimentos.

É inegável a dedicação das instituições da produção orgânica estadual ao fortalecimento do setor. O governo do estado e a Prefeitura do Rio têm sido interlocutores atentos da produção orgânica. As dificuldades de crescimento enfrentadas da PO solicitam, entretanto, que se avalie a adequação de suas atuais formas de coordenação e elenco de políticas públicas aos principais desafios que o setor, na fase atual, enfrenta.

Duas questões poderiam, assim, ser levantadas para discussão nas instâncias de coordenação da produção orgânica. A primeira diz respeito à construção do planejamento estratégico do setor: a definição de objetivos a serem alcançados nos próximos anos e das ações e recursos necessários para sua efetivação. Uma dificuldade é o fato de que as instâncias de coordenação da produção e da secretaria estadual de agricultura não parecem dispor hoje de um diagnóstico mais preciso da cadeia produtiva orgânica capaz de orientar objetivos e articular ações. A sugestão que aqui pode ser feita seria orientar mais esforços ao processo de construção do mercado de orgânicos em base a um planejamento dos passos a serem dados na cidade e no estado.

A segunda questão está voltada à discussão da relação entre o apoio público à produção orgânica e a importância do setor para o estado. $\mathrm{O}$ impacto econômico direto da 
produção orgânica ainda é restrito. Mas as externalidades positivas (saúde dos consumidores e proteção ambiental decorrentes da atividade) e seu potencial impacto positivo sobre as atividades de base agropecuária (abrir caminho para o desenvolvimento de produtos de qualidade no setor) são muito expressivas. Um apoio público em sintonia com o potencial de crescimento da PO destacando-se a importância das externalidades que cria redundaria provavelmente numa expressiva expansão do apoio à PO estadual.

Uma melhor adequação e precisão dos apoios aos entraves vividos pelo setor também seria esperada. A eficácia das ações de apoio tem base na existência de diagnósticos precisos e na definição de objetivos realistas, identificando instrumentos e mecanismos de apoio e articulando ações. A oferta de menores taxas de juro, a redução parcial de impostos e a equalização das condições oferecidas em outros estados são instrumentos menos eficazes quando se trata de desatar pontos de estrangulamento como os identificados para a PO.

\subsection{A completude da cadeia produtiva de orgânicos: as determinações cruzadas}

Pode-se pensar, também, em que medida a integração de novos setores à cadeia produtiva pode ser articulada pelas atuais instâncias de coordenação do setor. Se imaginarmos a implantação de um setor de processamento de frutas e legumes orgânicos, por exemplo, veremos que ela está condicionada pela ampliação da produção dessas matérias-primas. Esta, por sua vez, dependerá da existência de terras certificadas e da efetivação dessa demanda.

O desenvolvimento da oferta de proteína animal orgânica dependeria da existência de uma reserva de pastos certificados e do acesso a rações, vacinas e medicamentos orgânicos. Por seu lado, a produção de insumos e matérias-primas e as atividades de processamento necessitam de uma escala mínima de demanda, para se tornarem economicamente viáveis.

Consideremos também uma fábrica de rações orgânicas para criação animal. Para operar, ela necessita de garantias de abastecimento de seus insumos. Estes poderiam ser produzidos no estado, mas ainda não o são. Uma empresa desse tipo não poderá funcionar sem uma garantia de abastecimento. E os produtores potenciais não plantarão o produto sem garantia de mercado. A existência de sementes orgânicas de qualidade adaptadas à região produtora seria um expressivo fator indutor da produção desses insumos, pois limita incertezas. 


\subsection{Uma pequena síntese}

A atual escala da produção orgânica dificulta a construção da cadeia produtiva: ela se traduz em pequena demanda por fornecimento de insumos à produção e pouca oferta de matérias-primas orgânicas. Acarreta, assim, condições de forte incerteza para o surgimento de empresas produtoras de insumos ou de processamento industrial.

A horticultura orgânica - principal núcleo da produção orgânica do estado dificilmente poderia assumir o papel de principal vetor de expansão da produção orgânica. Ela possui um grande espaço de consolidação, em particular quanto ao processamento industrial de frutas e legumes orgânicos, mas seus produtos, por serem perecíveis, possuem limitado poder de barganha junto ao comércio e estão sujeitos à instabilidade de preços. Não é assim um setor onde o retorno é elevado e com grandes possibilidades de reinvestimento.

A oferta de produtos orgânicos no grande varejo ampliou-se, de forma discreta, nos últimos anos, em duas direções: produtos processados - em particular massas - com marcas do supermercado e a empresa Korin, que oferta macarrão, arroz, café, frango, mel, ovos, água mineral e vegetais minimamente processados, todos livres de agrotóxicos. Trata-se, entretanto, de empresas com recursos econômicos limitados e que não esperam retorno financeiro imediato. Condições que não existem hoje, ao menos nessa escala, na PO estadual.

\section{Observações finais}

Este trabalho sugere para discussão que a efetivação do potencial de mercado da produção orgânica em nosso estado passa por quatro vetores.

- A divulgação sistemática da qualidade da produção orgânica e das principais externalidades positivas que propicia, em um ambiente institucional ativo no controle da qualidade dos alimentos ofertados no mercado.

- A construção de uma cadeia produtiva mais completa envolvendo produtos de origem animal, processados industriais, insumos e matérias-primas orgânicas sem os quais a PO não pode se constituir em efetiva alternativa alimentar.

- O reforço e melhor coordenação da infraestrutura de pesquisa dando-lhe melhores condições de enfrentamento dos pontos de estrangulamento tecnológico da produção, voltando-se em particular para a ampliação da cadeia produtiva e a diminuição dos custos de produção. 
- A construção de uma agenda de políticas de apoio orientada por um planejamento estratégico objetivando desatar os principais pontos de estrangulamento da produção orgânica do estado e criar melhores condições de desenvolvimento autônomo do setor.

\section{Bibliografia}

ASSIS, M. Diagnóstico da agricultura orgânica no Rio de Janeiro e propostas para sua difusão. Seropédica, ERJ: UFRRJ, 1993.

BUANAIN, A. M. e BATALHA, M. O. A cadeia produtiva de produtos orgânicos. Brasília: MAPA, 2007. Volume 5. (Série Agronegócios)

CARVALHO, R. L. Canais de comercialização para a produção familiar da região serrana do RJ. Relatório de Pesquisa. Rio de Janeiro: PRODETAB-EMBRAPA, 2001.

A evolução da economia fluminense. In: FAURÉ, Y. e HASENCLEVER, L. Desenvolvimento local no Estado do Rio de Janeiro. E-papers. Rio de Janeiro, 2005.

. Gargalos setoriais da produção orgânica do Estado do Rio de Janeiro. Relatório de pesquisa. Rio de Janeiro: REDETEC, 2011.

FONSECA, M. F. A institucionalização do mercado de produtos orgânicos no mundo e no Brasil, uma interpretação. Tese de Doutorado. Seropédica, ERJ: UFRRJ, 2005.

. A legislação da agricultura orgânica: avanços e entraves para a produção familiar. In: CONGRESSO DA ASSOCIAÇÃO BRASILEIRA DE AGRO ECOLOGIA. Vitória, ES, 2007.

FONSECA, M. F. e ASSIS, I. B. Panorama da produção, do mercado e do consumo nacional de produtos orgânicos. In: BUAINAIN, A. C. e BATALHA, M. (orgs). Cadeia produtiva de produtos orgânicos. Brasília: MAPA, 2007. Volume 5. (Série Agronegócios)

MELÃO, I. B. et allii. O mercado de orgânicos no Paraná: caracterização e tendências. Cadernos de agroecologia, vol. 2, n. 1. Curitiba: IPARDES, 2007.

ORMOND, J. G. P. Agricultura orgânica: quando o passado é futuro. BNDES Setorial, n. 25, Rio de Janeiro, 2002.

RELATÓRIO PRODETAB - EMBRAPA. Rio de Janeiro. 2004. A evolução recente da agricultura fluminense. In: FAURÉ, Y. e HASENCLEVER, L. O desenvolvimento local no ERJ. E-papers. Rio de Janeiro, 2005. 